\title{
The Effect of Cooperative Learning Type Think Pair Share with Autograph on The Mathematical Representation Ability Students
}

\author{
Yuli Ragelia Sinaga \\ Department of Mathematics \\ Education, Post Graduate \\ Universitas Negeri Medan \\ Medan, Indonesia \\ Corresponding email: \\ yuliragelia@gmail.com
}

\author{
Edi Syahputra \\ Department of Mathematics \\ Education \\ Universitas Negeri Medan \\ Medan, Indonesia
}

\author{
Faiz Ahyaningsih \\ Department of Mathematics \\ Education \\ Universitas Negeri Medan \\ Medan, Indonesia
}

\begin{abstract}
This research attempts the effect of Cooperative Learning type Think Pair Share (TPS) with Autograph on the mathematical representation ability students. The purpose of this study was to investigate the effect of Cooperative Learning type TPS with Autograph to the students Mathematical Representation Ability and the interaction between learning model with the initial mathematical abilities (KAM) to the students mathematical representation ability. The research samples comprised 36 XI 5 graders (experiment I class) and 36 XI 6 graders (experiment II class) from an Senior High School (SMA) in Medan. We used the quasi experimental design with Cooperative Learning type TPS with Autograph and Cooperative Learning type TPS without Autograph as the independent variables. The dependent variables included the mathematical representation ability. The instrument used consisting of KAM test and mathematical representation ability test. The analysis is used two way ANOVA. The research findings indicate that there is a significant effect of Cooperative Learning model type TPS with Autograph to the students mathematical representation ability and there is no significant interaction between learning model and KAM to the students mathematical representation ability.
\end{abstract}

Keywords-Cooperative Learning; Think Pair Share; Autograph; Mathematical Representation Ability

\section{INTRODUCTION}

The abundance of natural resources in a country is not necessarily a guarantee that the country will prosper, if its human resource education is neglected. A country that has a lot of natural resources if it is not handled by a qualified human being will one day experience disappointment. Efforts to improve human resources are a big task and require a long time. Improving human resources must be through a good and directed education process. The future of a country is largely determined by how the country treats education.

Education is a very important aspect because it is expected to be able to form skilled, creative and innovative human resources. Education emphasizes the learning process that aims to develop all the potential that exists in humans both cognitive, affective and psychomotor aspects. Formal education conducted in schools until now remains the main educational institution which is the center of human resource development supported by education in the family and society.

Mathematics as one of the means of scientific thinking is very necessary to develop the ability to think logically, systematically and critically in students. Similarly, mathematics is the basic knowledge needed by students to support the success of learning in higher education. Even mathematics is needed by everyone in everyday life. That is why students need to have sufficient mathematical knowledge to face the future.

Mathematical representation ability is part of the expected ability in mathematics learning. Representative skills need to be presented intensively so that students are actively involved in learning and the loss of impression that mathematics is a strange and frightening lesson.

Representative ability is one of the important and fundamental components to develop students' thinking skills, because in the mathematics learning process we need to link the material being studied and present ideas / ideas in various ways. Mathematics learning experts who are members of the NCTM establish mathematical representations as a separate ability standard that must be developed in the implementation of the mathematics curriculum in schools.

So important is the ability of mathematical representation in the learning process, but in reality the mathematical representation ability of high school students is still low. The description in this field is in accordance with the TIMSS report [1] which shows students' ability in presenting mathematical ideas or concepts in the material of division and numbers; algebra; geometry; as well as data representation, analysis, and opportunities including low. It can be assumed that high school students in Indonesia have a low mathematical representation. For example, when students are asked to make an equation from the table that presents the relationship between two variables, the representation ability of Indonesian students is $27 \%$. While the average international representation capability is $45 \%$. Thus there are differences in representation ability by $18 \%$.

To reinforce the authors' assumptions about this, the writer gives the following questions to several students: A shoe shop owner wants to fill his shop with men's shoes at least 100 pairs 
and women's shoes at least 150 pairs. The store can only accommodate 400 pairs of shoes. The advantage of each pair of men's shoes is Rp. 10,000.00 and the profit of each pair of women's shoes is Rp. 5,000.00. If the number of men's shoes should not exceed 150 pairs, then determine the biggest advantage that can be obtained by the shop owner! "

$$
\begin{aligned}
& \text { Alternative Solution: } \\
& \text { mathematical model: } \\
& \text { By example: } \\
& \text { men's shoes }=\mathrm{x} \\
& \text { women's shoes }=\mathrm{y} \\
& \text { System Inequality } \\
& \mathrm{x}+\mathrm{y}=400 \\
& 100 \leq \mathrm{x} \leq 150 \\
& 150 \leq \mathrm{y} \leq 250
\end{aligned}
$$

the objective function is $\mathrm{F}(\mathrm{x}, \mathrm{y})=10,000 \mathrm{x}+5,000 \mathrm{y}$

From the inequality system, the graph is obtained as follows:

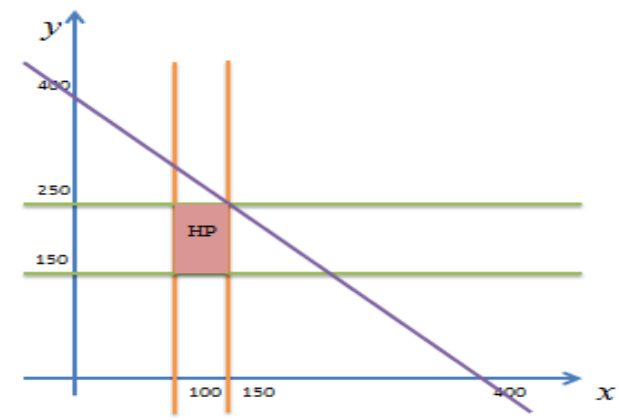

Fig 1 . Graph from the inequality system

From the graph it shows that the maximum gain is at the point $(150,250)$. Then the maximum value of the objective function $F(x, y)=10,000 x+5,000 y$ is:

$$
\begin{aligned}
\mathrm{F}(150.250) & =10,000(150)+5,000(250) \\
& =2,750,000
\end{aligned}
$$

Thus, the greatest advantage to be gained store owner is Rp $2,750,000.00$ Fig 2

The answers written by one of the students can be seen in

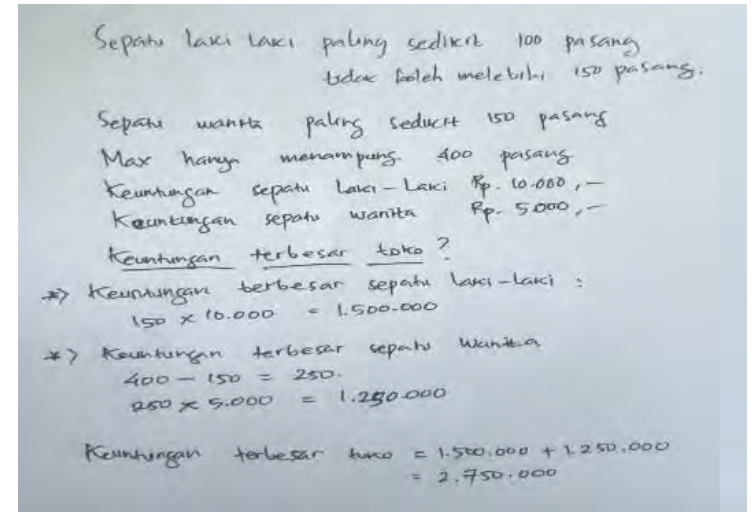

Fig 2. Example of the Answer of One Student

The student answer process above shows that in the aspect of symbolic representation, students can work on mathematical representation problems, but in terms of representation in form of images (visual representation) and translate problems into mathematical models (verbal representations) students experience difficulties. Through the students' answers in solving the representation ability problem, $65 \%$ of students were weak in utilizing the mathematical representation abilities that students have.

Representations will appear clearly in sufficient quantities and are relevant to students' abilities if learning is carried out with approaches that allow representations to occur. Knowledge that is seen as one of the approaches that can make students active in constructing their knowledge is a cooperative learning approach.

In addition, it is important to remember that every student has different abilities in understanding mathematics. From a group of students will always be found students who have high, medium and low abilities. Awareness of the different abilities of students is not solely inherent from birth, but can also be influenced by the environment.

The initial skills and characteristics of students are relevant knowledge and skills, including the background information on student characteristics that he has at the time of starting a teaching program. Problems often occur in estimating students' abilities and circumstances. Sometimes the estimate is too low (under estimate), but sometimes the estimate is too high (over estimate).

The learning model that is thought to improve mathematical representation ability and self-efficacy students' are cooperative learning type TPS. TPS is a type of cooperative learning cooperative learning model that puts students in pairs to complete academic assignments through three stages: Think (think), Pair (pair), and Share (share). This TPS learning model was developed by Frank Lyman and colleagues from the University of Maryland. This learning model provides opportunities for students to work alone and work with others [2]. Furthermore [3] states that TPS type cooperative learning can train and develop students 'thinking skills and activities, because students build knowledge through their own exploration and students' knowledge can also develop through the transfer of mindset with other students so that students are able to combine and compare their own mindset with other students' mindset. This learning model can stimulate high-level thinking skills because with this learning model the potential 
possessed by students is thoroughly excavated as much as possible.

From the expert's opinion it can be concluded that the TPS type cooperative learning model is a learning model that involves the activeness of students in learning, because students are told to practice individually, then students are told to work together in pairs and then the discussion results are presented in front of the class. And from the opinion of the expert, the researcher also suspects that this type of TPS cooperative learning model can improve mathematical representation ability and self-efficacy students'.

Then in cooperative learning technology takes a very important role for the ease of the learning process. Computers are one form that indicates the development of technology and information today. Almost all activities in human life can be facilitated by computer assistance. With the computer will greatly help the learning process. No wonder, as the advancement of technology was marked by the widespread use of computers in the world of education, making computers as one of the learning media that received recommendations to be used as a tool in learning that received recommendations for use as a tool in mathematics learning. This is supported by Zarlis (in Rusdi, 2008: 2) "Technology experts in education say that computers are suitable to be used as a tool in the learning process. In education, especially computer mathematics learning functions as atool, tutor and tutee.

The use of ICT is one of the six principles of school mathematics, "Technology is essential in teaching and learning mathematics; it influences the mathematics that is taught and enhances students' learning."For application in class, the use of ICT can be integrated with several learning. As Karnasih said, "There are four different approaches that can be implemented in integrating ICT teaching and learning mathematics: (1) Expository learning;(2) Inquiry based learning; (3) Cooperative learning; (4) Individual learning [4].

There are many software mathematicalor software that can be used on computers as an ICT-based learning media to make the delivery of mathematics easier, more interesting and students motivated to learn, one of which is software Autograph. Autograph is software that can be used in mathematics learning, especially in two-dimensional and threedimensional material.

Based on the description above, the researcher is interested in conducting a research entitled "The Effect of Cooperative Learning Type Think Pair Share with Autograph on The Mathematical Representation Ability XI grade students"

\section{METHODS}

This study used an experimental method inform quasi experimental design. Method quasi experimental design is a design that has a control group, but cannot fully function to control external variables that affect the implementation of the experiment. The research instrument that changed the mathematical representation ability test consisted of 3 essay questions. After the test, then the data is analyzed in the form of homogeneity test using the F test, test for normality by using Kolmogorov-Smirnov and test hypotheses using twoway ANOVA with interaction. Calculation of the results of the study using Excel 2010 and SPSS 19.

\section{RESULTS AND DISCUSSIONS}

Discussion of the research that will be presented by the researcher is to describe and discuss the results of the study. Guided by relevant theories and research and then will be linked to the results of research researchers in the field. As for the description of several factors related to this research are as follows:

\section{A. Mathematical Representation Ability}

From the calculation results, it was found that there was an influence of Autograph-assisted TPS type cooperative learning on students' mathematical representation abilities. In other words, the influence of Autograph-assisted TPS-type cooperative learning on mathematical representation abilities is better than TPS-type cooperative learning without Autograph's assistance with mathematical representation capabilities. Students who participate in learning with Autograph-assisted TPS-type cooperative learning have become accustomed to being active in solving problems thinking individually to get concepts. Because the learning process is not just transferring knowledge from the teacher to students, but a process that is conditioned or sought by the teacher, so that students are active in various ways to build their own knowledge. In line with the piaget which emphasizes the importance of motivation and facilitation of students by the teacher. In order for children's intellectual development to take place optimally, they need to be motivated and facilitated to build theories that explain the world around.

In accordance with the mathematical characteristics that are abstract, then in the process of mathematical problem solving requires representation capabilities, this is reinforced by the opinion of [5] states that representation is needed because when students make representations, the student has tried to express ideas about abstract mathematics so students then display the model as a form of substitute situation that is used to find the problem solving faced. Based on Asmara's opinion it is clear that mathematical representation ability is closely related to mathematics because the process of success in mathematical problem solving is supported by mathematical representation capabilities.

According to [6] he stated the same thing that students who are able to apply their representational abilities will be able to more easily solve problems and more easily understand them. This means that in solving mathematical problems the ability to represent has an important role so that students can express their mathematical ideas in the process of solving these problems.

The representational capabilities raised by students are expressions of mathematical ideas or ideas displayed by students in their efforts to find a solution to the problems they are facing [7]. Representation is very instrumental in efforts to develop and optimize students' mathematical abilities. According to Alhadad [8] representation is an expression of mathematical ideas as a model used to find solutions to the problems they face as a result of their interpretation of the mind.

OECD PISA states that there are eight components of mathematical competence, one of which is the mathematical representation ability of students [9]. Every five years PISA conducts prestigious competition activities in the field of 
science, especially mathematics, but Indonesia has always been a backward sequence. For this reason, researchers feel the need to focus this research on mathematical representation abilities, because to support Indonesian students to be more active and able to in the future PISA.

In his research [10] realized that the importance of having mathematical representation ability in generating mathematical ideas that are able to develop the way of thinking of each student for the achievement of problem solving in mathematics. The results of his research show that students who have good mathematical representation ability are easier to solve mathematical problems and can solve problems easily. The achievement of students' problem solving in developing mathematical representation abilities is very different because each student has different representation abilities.

The explanation above is supported by learning theory that supports the mathematical representation ability found in [11] "Piaget divides the development of children's learning into four parts and the last part is the abstract stage, at this stage the child has been able to think abstractly and see the symbol - symbols or symbols ". This stage describes the ability of students who have been able to distinguish concrete and abstract domains, and at this stage representation skills have begun to develop in students.

Bruner [11] describes the stages of children's mental development into three stages: the active stage, the iconic stage and the symbolic stage, at this symbolic stage children have been able to manipulate symbols directly without linking them to other objects. . It can be concluded that representation ability is already present in students in accordance with their cognitive development stages, therefore teachers can develop and enhance these representational abilities so that they can support the success of their learning and the success of education in Indonesia, so the teacher's job is to choose an appropriate learning model to be able to help improve the representation ability, therefore the researcher focused this research also on TPS type cooperative learning which can be a reference and alternative for teachers to improve mathematical abilities especially mathematical representation abilities.

\section{B. Interaction between Learning Model with KAM on Representation Capability}

From the results of the analysis of research calculations conducted on learning models with KAM (low, medium, high) on the ability of student representation indicates that there is no interaction. That is, the difference in the average of the mathematical representation ability test between students in the low, medium and high categories that was taught through cooperative learning with Autograph-assisted TPS type with students who are taught with TPS type cooperative learning without Autograph's help is not significantly different. This shows that there is no influence together which is contributed by the TPS type cooperative learning model (assisted by Autograph and without the help of Autograph) with KAM (low, medium, high) of students towards students' mathematical representation abilities.

There are several things in the study that indicate the possibility of no interaction between the learning model and KAM of mathematical representation abilities, including (1) the indicator of KAM test instrument that is given does not represent the prerequisite material for the subjects taught at the time of research, (2) KAM test form in the form of multiple choices, allows students to answer questions by simply guessing the answers to the options that have been provided, and (3) related to the grouping of KAM, this is due to the grouping of students' KAM. Researchers are guided by the acquisition of students' scores on the KAM test taken from national exam questions that do not reflect the expected mathematical representation abilities of students, so that students who have high, medium, and low math initial abilities have not represented abilities the actual beginning of mathematics.

In addition to KAM factor, there are other possible factors that cause no interaction, namely the difference in learning used. This study uses a TPS type cooperative learning model Autograph assisted and TPS type cooperative learning without the help of Autograph. Theoretically, in TPS type cooperative learning Autograph assisted There are stages in which students discuss groups, demand work and present work that enables interaction between groups and teachers play a role in conditioning and motivating students to use groups as a means of discussing and exchanging ideas. However, based on observations during the research, most students were still not active in groups, even just keeping quiet without communicating with their group friends. Some students only bothered their friends, while their group friends preferred to answer the student activity sheet (LAS) questions themselves. So that learning is expected to be less than optimal. Thus the learning model is thought to be the reason for the lack of interaction between the learning model and KAM of students' mathematical representation abilities.

Another possibility that indicates the acceptance of this hypothesis occurs because there are many other factors that influence students, such as relatively short research times, students who are active in school organizations must divide their time while learning mathematics and organizational activities so as not to allow students to take mathematics lessons. time and cost limitations, such as student attitudes and interests, students' family economic background, teacher competence both in mastering the material and in managing the class and so on, so that research is solely influenced by the learning model applied.

In addition, due to the selection of samples using amethod simple random sampling by giving equal opportunities to each member in a population to be used as a sample used by researchers in sampling so as to allow the distribution of uncontrolled variables to be uneven in each group, so Research data in the field does not support the third hypothesis of this study which ultimately leads to the acceptance of $\mathrm{H} 0$.

\section{CONCLUSIONS}

There is the effect of Cooperative Learning type TPS with Autograph to the students mathematical representation ability, when viewed from the difference in the average cooperative learning type TPS assisted by Autograph with cooperative learning type TPS without the help of Autograph in influencing the results of mathematical representation capabilities while constantly considering other factors that are not controlled in influencing the ability of mathematical representation. 
There is no interaction between learning model with KAM to the students mathematical representation ability, due to the absence of influence together contributed by the learning model (cooperative learning type TPS assisted by Autograph and without the help of Autograph) with KAM (low, medium, high) students towards students' mathematical representation abilities.

\section{References}

[1] Mullis and Martin, "TIMSS 2011 International Result in Mathematics", Boston: International Study Center, 2012.

[2] H. Isjoni, "Pembelajaran Kooperatif Meningkatkan Kecerdasan Komunikasi Antar Peserta Didik", Pustaka Pelajar. Pekan baru, 2009, pp. 112.

[3] Trianto, "Model-model Pembelajaran Inovatif Berorientasi Konstruktivistik", Jakarta: Prestasi Pustaka, 2007, pp. 61.

[4] I. Karnasih, "Paper in International Workshop: ICT for teaching and Learning Mathematics", Unimed, Medan, 2008. (In Collaboration between UNIMED and QED Education Kuala Lumpur, Malaysia, 23-24 May 2008)
[5] A. Asmara, "Mathematical Representation Ability And Self Confidence Students Through Realistic Mathematics Approach", International Seminar on Innovation in Mathematics and Mathematics Education 1st ISIM-MED 2014, Department of Mathematics Education, Yogyakarta State University Yogyakarta, ISBN : 978-602-1037-00-3, 2014, pp. 139.

[6] M. Sajadi, et al., "The Examining Mathematical Word Problems Solving Ability under Efficient Representation Aspect", International Scientific Publications and Consulting Service, Vol. 2013, 2013, pp. 11

[7] NCTM, "Principles and Standarts for School Mathematics". Reston: NCTM, 2000, pp. 67.

[8] A. E. Astin and Bharata, Haninda, "Penerapan Pendekatan Open-Ended Dalam Pembelajaran Matematika Terhadap Kemampuan Representasi Matematis Siswa", Lampung. ISSN: 2502-6526, 2016, pp. 631-638.

[9] E. Debrenti, "Visual Representations In Mathematics Teaching: An Experiment With Students". Acta Didactica Napocensia. Vol. 8 No. 1. ISSN 2065-1430, 2015, pp.19

[10] A. Minarni, et al., "Mathematical Understanding And Representation Ability of Public Junior High School in North Sumatera", Journal on Mathematics Education, Vol. 7, No. 1, ISSN 2087-8885, 2016, pp. 4356.

[11] L. Cope, "Math Manipulatives: Making the Abstract Tangible", Delta Journal of Education", Vol. 5 Issue 1, ISSN 2160-9179, 2015, pp. 14. 